\title{
Human simulator - a tool for predicting thermal sensation in the built environment
}

Barbara Koelblen ${ }^{a, b}$, Agnes Psikuta $^{a}$, Anna Bogdan $^{b}$, Simon Annaheim ${ }^{a}$, René M. Rossi ${ }^{a}$

${ }^{a}$ Empa, Swiss Federal Laboratories for Materials Science and Technology, Laboratory for Biomimetic Membranes and Textiles, Lerchenfeldstrasse 5, 9014 St. Gallen, Switzerland

${ }^{\mathrm{b}}$ Air-Conditioning and Heating Department, Warsaw University of Technology, Nowowiejska 20, 00-653 Warsaw, Poland

\author{
barbara.koelblen@empa.ch \\ agnes.psikuta@empa.ch \\ anna.bogdan@pw.edu.pl \\ simon.annaheim@empa.ch \\ rene.rossi@empa.ch
}

Corresponding author:

Agnes Psikuta

Empa, Swiss Federal Laboratories for Materials Science and Technology, Laboratory for Bio-

mimetic Membranes and Textiles

Lerchenfeldstrasse 5, 9014 St. Gallen, Switzerland

Tel.: +41587657673

E-mail: agnes.psikuta@empa.ch

This document is the accepted manuscript version of the following article:

Koelblen, B., Psikuta, A., Bogdan, A., Annaheim, S., \& Rossi, R.M. (2018). Human simulator - a tool for predicting thermal sensation in the built environment. Building and Environment. https://doi.org/10.1016/ j.buildenv.2018.03.050

This manuscript version is made available under the CC-BY-NC-ND 4.0 license

http://creativecommons.org/licenses/by-nc-nd/4.0/ 


\section{Abstract}

One of the challenges for engineers designing indoor environments is merging the need for energy savings with providing thermally comfortable conditions for the occupants. Since the best way to evaluate thermal comfort, i.e. direct enquiry, is at the same time the most costand time-consuming one, various modelling tools are widely used. However, in order to assess complex heterogeneous environments created by novel building systems, there is a need for more sophisticated and precise tools.

In this paper, we present a new human simulator methodology for indoor environmental research, combining three tools to predict thermal sensation, namely, a thermal manikin, a thermoregulation model, and a thermal sensation model. Thanks to the thermoregulation model's control, the thermal manikin is capable of mimicking the thermo-physiological response of a human exposed to chosen environmental conditions, which provides reliable input data for advanced thermal sensation models. Along with presenting this concept, the performance of a commercially available human simulator was demonstrated on five validation examples representing office-like conditions for which thermal sensation was predicted with satisfactory accuracy. Based on the presented results, we discussed the capabilities and limitations of human simulators for indoor environment research such as the benefits of performing measurements directly in the assessed environment with real garments, and the challenges related to the manikin's accuracy. The presented human simulator approach is suitable to apply in the building's design process, as well as the development of new solutions for conditioning indoor spaces, and can support the evaluation of existing buildings. 


\section{Keywords}

Thermal sensation models, thermo-physiological model, thermal manikin, human simulator, indoor environments design, subjective judgement 


\section{Introduction}

1.1 Energy savings and thermal comfort - challenges for indoor environment design

As people in developed countries spend a vast majority of their time indoors [1], it is of paramount importance to design comfortable indoor spaces to ensure the well-being and health of occupants, and thus support productivity at work. New heating, ventilation and airconditioning (HVAC) systems are nowadays developed in order to reduce the energy demand of buildings. They often make use of the benefits of not conditioning the entire building volume homogeneously, sometimes creating strongly heterogeneous environments [2], which supports the decrease in energy use while still providing acceptable conditions for the occupied areas (e.g., chilled ceiling, radiative panels, personalized ventilation as well as combinations of systems). Additionally, elements of building design such as glazing or solar shades contribute to the complexity of the indoor environmental conditions. Therefore, engineers and designers have to ensure energy saving strategies while creating thermally comfortable indoor spaces.

In a traditional approach to indoor spaces' design, occupants are considered as heat sources (together with heat gains from equipment or light [3]) whose presence may influence the desired thermal conditions and air flow in the room. A more user-centered approach shifts the interest towards how the environment influences the occupants' thermal perception and, more specifically, what element of the system might be the source of their discomfort. In the case of existing buildings where uncomfortable conditions are reported, a direct enquiry gives the opportunity to track the source of the problem: occupants can not only state how much discomfort they feel, but also give some precise information related to their individual work space (e.g., feeling of draught at the neck, excessive sun radiation, etc.). In order to 
adopt a similar approach at the design stage of buildings or new HVAC systems, a human subject study can be performed in a model environment or mock-up, including asking the subjects for thermal sensation and comfort feedback. However, such studies are costly and time-consuming, and ethical committee approval must be obtained prior to the trials, which requires longer study execution periods. Other possibilities to assess the thermal perception of the surrounding environment bring into play modelling solutions with various level of complexity.

\subsection{Modelling thermal sensation in indoor environments}

In the past decades, various thermal sensation and comfort models have been developed to evaluate thermal surroundings [4]. In this way, engineers and designers obtained a simulation tool to assess thermal conditions in the built environment with regards to their influence on the human thermal perception, based on environmental and personal parameters (typically, activity level and clothing). Since new, energy-efficient HVAC systems employ the benefits of individualized and localized thermal conditions [2], some advanced thermal sensation models capable of assessing such complex heterogeneous environments were developed (e.g. Dynamic thermal sensation (DTS) by Fiala [5] for transient conditions, models dedicated to local thermal sensation such as the Thermal sensation (TS) by Zhang [6], the models by Jin [7] and by Nilsson [8]). Additionally, such local thermal sensation models can support engineers to predict possible sources of the occupants' dissatisfaction at the design stage. For example, a global 'cold' thermal sensation might result from a 'cold' local sensation (e.g. neck due to draught) which overrules an initially 'neutral' whole-body sensation $[6,10]$. In this case, measures should be taken to improve a specific aspect instead of a global change (e.g. reducing draught at the neck instead of increasing the air temperature in the whole room). 
In order to enable the evaluation of thermal sensation in heterogeneous environments, thermal sensation models need more advanced input parameters, i.e. spatial distribution of environmental conditions or thermo-physiological parameters, such as local skin and core temperatures. On one hand, the reliability of thermal sensation predictions is directly linked to the model's own validity and performance. On the other hand, the accuracy of all input parameters, i.e., how well they represent the analyzed scenario, also influences the thermal sensation predictions (e.g. [11-13]). In a recent study by Koelblen et al. [12], the performance of several thermal sensation models was assessed, showing good accuracy of some models dedicated to transient and/or heterogeneous conditions (i.e., DTS by Fiala $[5,9]$ and TS by Zhang $[10,14])$.

In order to increase the accuracy of the input parameters for complex environmental conditions, thermal sensation models are used along with other simulation tools. Thermophysiological parameters (e.g. skin and core temperature) can be obtained from thermoregulation models. Such models require environmental and personal input data to predict the human physiological response to given environmental conditions. It can be assumed that the accuracy of input data values influences the accuracy of thermo-physiological predictions [15]. In the case of existing buildings, the accuracy of thermo-physiological predictions can be increased by replacing assumed environmental data by measured ones, reflecting real spatial or temporal non-uniform conditions (e.g., [16]). At the design stage, the environmental input parameters in complex environments can be modelled with CFD simulations, including all heating/cooling devices, air supply, etc. A virtual manikin is typically simulated in the CFD environment to represent a human occupant. This virtual manikin can be, in turn, directly coupled with a thermoregulation model, bringing the virtual manikin-environment interaction closer to real heat and mass transfer (e.g. [17-20]). However, a major drawback of such simu- 
lations is the simplified modelling of the clothing (static, global parameters, e.g. clothing thermal and evaporative insulation, clothing area factor), which does not take into account the complex heat and mass transfer mechanisms related to clothing. Furthermore, due to considerable computational power requirements, the geometry of the virtual manikin as well as its surroundings in CFD simulations often need to be simplified, which may lead to relevant inaccuracies in thermal sensation predictions. In a larger scale, the CFD simulation of the heterogeneous building spaces with complex boundary conditions and possibly added details of humans present in the space is difficult to validate directly (number and placement of sensors, disturbing the air flow, availability of physical model or actual building space equipped with evaluated systems).

Another approach to acquire the needed input parameters is to use a human-shaped thermal manikin that can be directly exposed to the evaluated surroundings and clothed in real garments. Modern thermal manikins have several independently controlled body segments and are equipped with sweating, breathing, and/or walking functions. However, they are typically operated in a constant surface temperature mode (e.g., as for clothing thermal insulation measurements [21]), which does not reflect the heterogeneous humanlike skin temperature distribution. Two other commonly used control modes are the constant power mode, which represents a given metabolic rate associated to the performed activity, and the so-called 'comfort mode', which allows adjusting the local skin temperatures based on heat loss according to comfort equations [22]. Nevertheless, these two modes do not incorporate active thermoregulatory processes (vasomotion, sweating, and shivering), providing only an approximated heterogeneous skin temperature distribution. Moreover, no information about further thermo-physiological parameters is available in such tests (e.g. core temperature, sweat rate, 
skin blood flow), making it impossible to apply thermal sensation models relying on such input parameters.

A first system combining thermo-physiological predictions and a physical tool (i.e., a thermal manikin) for the evaluation of human thermal sensation and comfort in indoor environments was developed by Foda and Siren [23],[24]. In their approach, measured environmental parameters were fed to the thermoregulation model (similarly as in [16]). The predicted local skin temperatures were then set on the manikin and the resulting heat fluxes measured on the manikin were used to predict thermal sensation. The reliability of this system, however, has been validated only based on equivalent temperatures related to thermal sensation without assessing the accuracy of skin temperature predictions. Additionally, the lack of sweating ability of the used thermal manikin limits its range of use.

1.3 The human simulator - combining advantages of various tools for predicting thermal sensation

In the last decade a new type of tool has been developed, defined as a human simulator with thermoregulation model control, or so-called 'adaptive manikin' [15], consisting of a physical manikin coupled to a model of human thermo-physiology. The physical manikin dressed with chosen clothing is directly exposed to the evaluated environment. The thermoregulation model connected to the manikin predicts the human thermo-physiological response based on real-time data exchange with the thermal manikin, enabling a realistic skin temperature and sweat rate distribution on the manikin. The human simulator could be a good source of thermo-physiological input values for a thermal sensation model, which makes it a promising tool for engineers to design thermally comfortable indoor spaces. 
Although several thermo-physiological human simulators based on full-body manikins have been developed up-to-date [15], most of them were developed and used in clothing research or in automotive industry. The existing systems include a thermoregulation model coupled to a single-sector simulator [25-27], a full-body manikin [28-37], or a body-part manikin (human head manikin) $[38,39]$. Most of the existing full-body human simulators have been validated only qualitatively and/or with a limited number of validation cases (up to 8 validation cases by system [26,28,30-37] according to [15]) and without evaluating the individual components of the simulators. None of the systems has been evaluated with regards to using it for thermal sensation predictions indoors.

\subsection{Scope of the study}

In this paper, a methodology for performing human simulator tests in indoor environment research is presented. The proposed approach combines the strengths of three simulation and modelling tools to predict occupants' thermal sensation and can be applied to support the design process of buildings or to evaluate existing spaces. The performance of such a model-controlled human simulator for predicting thermal sensation was evaluated based on the 'Newton' manikin (Thermetrics, US) coupled to the human thermoregulation model within the Taitherm Manikin PC ${ }^{2}$ software (Thermoanalytics, US), which is the only commercially available coupled system up to date. The thermal sensation predictions were computed based on two models using thermo-physiological input parameters, namely, the DTS by Fiala $[5,9]$ and the TS by Zhang $[10,14]$. Additionally, thermal sensation predictions from both models were calculated based on a purely virtual simulation, that is, with the thermoregulation model as the direct source of input for the thermal sensation models. Five validation cases were presented to show the accuracy evaluation of both thermo-physiological and thermal sensation predictions obtained in purely virtual simulations and in human simulator 
tests. The opportunities and constraints of the human simulator in comparison to purely virtual simulations are discussed with regards to thermal sensation predictions in the built environment, namely, focusing on long duration of exposures with office-work level of activity, in steady-state or moderate transient, close-to-thermoneutral conditions.

\section{Human simulator for indoor environmental research}

\subsection{Human simulator concept and system components}

The human simulator for predicting thermal sensation of occupants of indoor spaces is a combination of three tools: a thermal manikin, a thermoregulation model, and a thermal sensation model. The human-shaped thermal manikin is responsible for measuring the total thermal influence of the surrounding environment, including the heat and mass transfer through the clothing and contact surfaces (e.g., seat). This is the basis for thermophysiological predictions from the thermoregulation model which are in turn used to control the thermal manikin in the next time-step by fixing the target set-points as predicted by the model. Thanks to this feedback loop, the thermal manikin 'adapts' itself to the given conditions, representing a humanlike surface temperature distribution and sweating. It is characteristic for the human simulator measurements that the thermal manikin is not performed in steady-state, i.e. it follows the dynamically changing target values predicted by the thermoregulation model which are set on the manikin in regular intervals (typically not longer than 1 minute). Finally, the predicted thermo-physiological parameters from the thermoregulation model are used as input values for the last tool, that is, the thermal sensation model responsible for translating theses parameters into a rating on a thermal sensation scale. Figure 1 presents the relationships and data flow between the system components. 


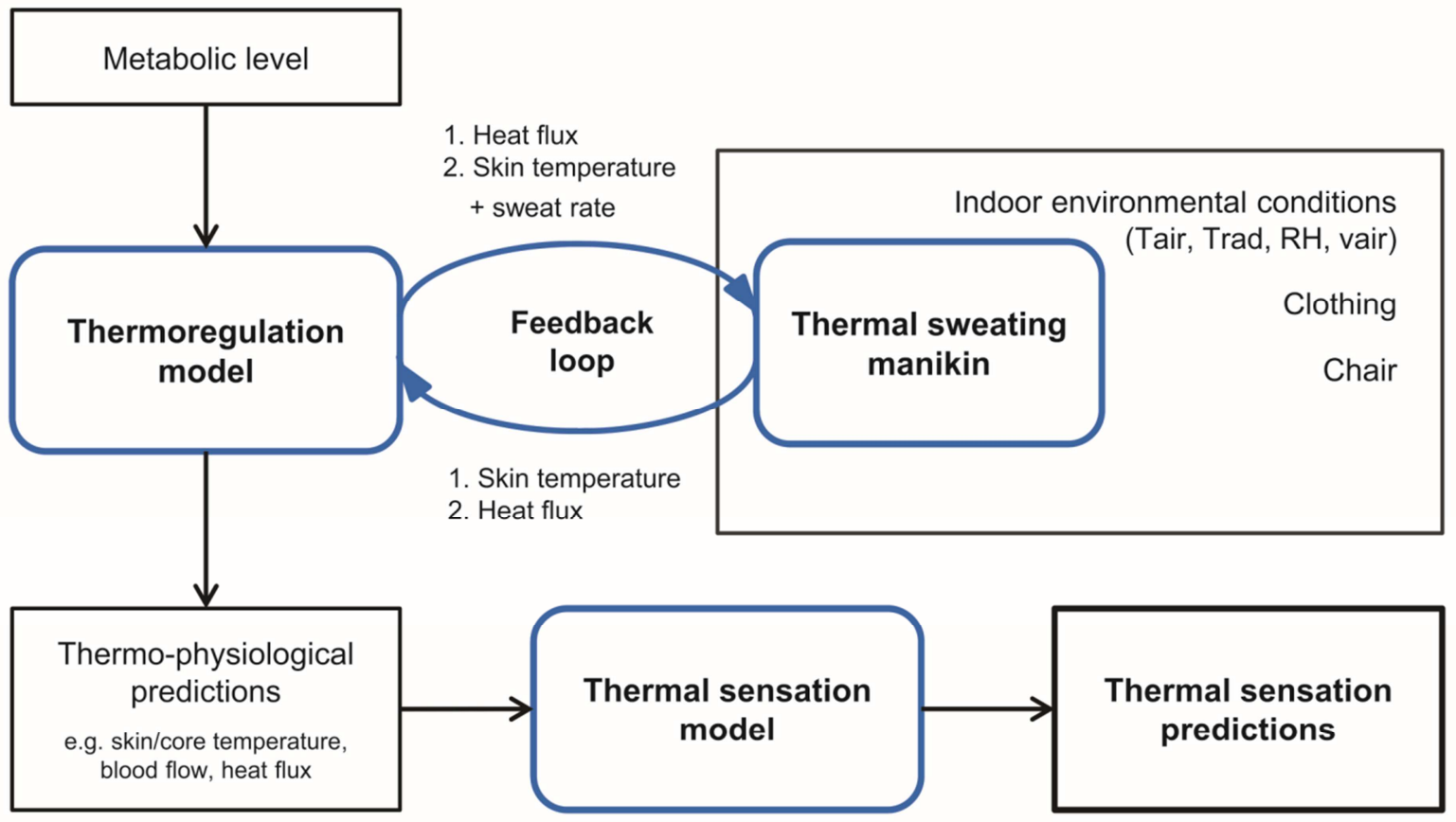

Figure 1 Data flow and relationships between the system components (human simulator system marked in blue), where 1 - parameters exchanged in the feedback loop when coupling with boundary conditions type 1 is applied, and 2 - using boundary conditions type 2

The human simulator requires real-time data exchange between the thermal manikin and the thermoregulation model. Two coupling methods enabling such a data exchange between these two components have been applied so far, differing in controlled and controlling parameters due to different boundary conditions for the thermoregulation model. In the first coupling method (boundary conditions type 1, or Dirichlet approach, Figure 1), the thermoregulation model calculates heat flux and sweat rate set-points, i.e., the target parameters' values for the manikin. The local skin temperatures measured afterwards on the manikin's segments, resulting from the influence of environmental conditions and clothing applied, are then used as a feedback for the thermoregulation model to predict new set-points for the manikin. In the second method (boundary conditions type 2 or Neumann approach, Figure 1), the local skin temperatures and sweat rates predicted by the model are set on the manikin, with the heat fluxes measured by the manikin used as the feedback for the thermo- 
physiological model. In both cases the thermoregulation model predicts all thermophysiological parameters (e.g. skin blood flow, core and skin temperature etc.) which can then be used for computing thermal sensation predictions. The thermal sensation predictions can be calculated when post-processing the data, without including the model into the feedback loop (Figure 1).

One important aspect in the coupling procedure is the agreement between the thermal manikin and the thermoregulation model spatial resolution. Advanced thermoregulation models generally have a finer resolution than existing manikins. For example, the body parts in the model are often divided into anterior, posterior, inferior, and superior sectors (for some models the resolution is even finer), whereas typical manikins have either one or two sectors per body part (e.g., entire forearm, or front and back upper leg, respectively). In order to allow the data exchange between these two tools, the coupling must include a conversion of the data, e.g., the skin temperature and sweat rate from the model's predictions for all sectors of the forearm is area-averaged and applied to the single-sector forearm body part of the manikin, and the resulting heat flux from the manikin (one value) serves as the input value for the model for all sectors of the forearm. Additionally, some further calculations might be needed to adjust the surface area of a given body part/sector if there is a lack of agreement between the dimensions of the manikin and of the human body as represented in the thermoregulation model.

Operating the manikin with thermo-physiological control entails a need for good accuracy of the manikin in spatially and temporally transient conditions to be able to follow the dynamic changes imposed by the thermoregulation model, which can be assessed following the methodology described by Psikuta et al. [40]. In our study, the 'Newton' sweating manikin was used (Thermetrics, US), which is shaped as a $50^{\text {th }}$ percentile Western male body form with 
26 individually controlled segments. In this manikin, the surface temperature is measured with embedded resistance wires, resulting in one temperature value per segment. Three body parts, namely the hip, upper leg, and lower leg, are further divided into front and back segments, enabling tests performed in a seated position where the chair is in contact with the posterior segments. Additionally, the thermal manikin needs to be equipped with a sweating system with dynamic adjustment of the sweat rate for each body segment in order to simulate the evaporative heat loss from the body. The sweating system of the 'Newton' manikin consists of a water supply system with sweating outlets evenly distributed over the manikin's surface complemented with a tight-fitting fabric skin delivered with the manikin that was shown to have very good wicking properties resulting in humanlike skin cooling by sweating [41].

An extensively validated thermo-physiological model was used in this study, namely, the thermoregulation model by Fiala $[5,42,43]$, which has been shown to provide reliable skin and core temperature predictions $([12,43-45])$ and is implemented in the Manikin PC $^{2}$ module (Taitherm software, Thermoanalytics, US). The coupling with the 'Newton' manikin in this system is based on the boundary conditions type 1 (Figure 1). It should be noted that thermophysiological predictions from various implementations of the same model might differ from one another. Therefore, it is advised to confirm the performance of the used implemented version of the model (validations of the Manikin $P C^{2}$ implementation of the Fiala model have been reported in $[31,46,47])$.

Since the major interest in using human simulators for indoor environmental research is to accurately predict occupant's global or local thermal sensation or comfort, the model used to this end should be carefully selected. Therefore, the chosen model's performance has to be verified in validation cases and knowledge about the model's sensitivity towards the input 
parameters is beneficial when interpreting the model's predictions. Due to the specifics of the human simulator tests in which thermo-physiological parameters are predicted, we selected two thermal sensation models capable of predicting thermal conditions in transient and/or non-uniform conditions, namely, the DTS model by Fiala $[5,9]$ and the TS model by Zhang $[6,10,14]$. The TS model provides both local and whole-body thermal sensations. Both models showed a good performance in a recent validation study, with average root-mean-square deviation equal to 0.7 and 0.8 unit for DTS and TS, respectively [12].

The DTS model is based on the ASHRAE 7-point scale $[48,49]$, whereas the TS model uses an extended 9-point scale, with +4 as 'very hot' and -4 as 'very cold'. Such an extended scale has been selected by the model's author to expand the possible votes for the evaluation of thermal sensation in vehicles [6] and has also been used for collecting votes in indoor environment research (e.g., [50-52]). The DTS predictions are based on core and mean skin temperatures, and the rate of change of mean skin temperature, whereas TS predictions are calculated from mean and local skin temperatures, and the rate of change of core and local skin temperatures. In this study, DTS was calculated based on equations by Fiala et al. [9], and additional clarifications were obtained from the model's author to ensure proper calculation of thermal sensation. The TS predictions were calculated directly in the ManikinPC ${ }^{2}$ software where the TS thermal sensation model is implemented based on the equations by Zhang et al. $[10,14]$.

\subsection{Validation procedure}

To validate the thermal sensation predictions from human simulator tests, experimental studies with human subjects need to be selected from the literature (or carried out) with conditions similar to the intended use of system. For example, in the case of office-like environ- 
ments the validation exposures should not only have appropriate ambient conditions and clothing, but also ought to be long enough (e.g., representing a 8-hour work day), which might be challenging as the vast majority of human subject studies addressing thermal sensation last 3-4 hours. It is also strongly recommended to choose exposures where both thermo-physiological parameters and thermal sensation votes were recorded to be able to separate the sources of inaccuracies by evaluating the reliability of the two models independently. To this end, the thermo-physiological parameters (typically skin and core temperature) predicted in the human simulator test are compared with the temperatures measured in the experimental study, and the thermal sensation predictions are validated against the human subjects' votes.

The reference experimental studies for validation ought to be carefully selected with regards to their quality, since poorly described experimental protocol might lead to wrong assumptions of test conditions. Studies with a high number of participants are preferred as more credible (various literature sources reported between 20 and 30 subjects as the sufficient sample size, as reviewed by Van Craenendonck et al. [53]). Additionally, knowledge about the pre-exposure conditions supports starting human simulator tests from an appropriate body state (i.e., initial manikin's surface temperature distribution). Finally, using the same clothing and furniture (e.g., chair) as in the original experiment is recommended.

Human simulator tests can be performed directly in the assessed indoor environment (e.g., office) or in a room where the chosen conditions are reproduced (e.g., climatic chamber). The manikin dressed with the needed clothing ought to be preconditioned to a suitable body state represented by local initial surface temperatures. This probable temperature distribution can be obtained from a virtual simulation in the thermoregulation model with pre-exposure conditions corresponding to the ones reported in the experimental study. 
Typically, the thermoregulation model requires an input value to simulate the metabolic level representing the activity from the experimental study, which can be constant or vary throughout the exposure (e.g. simulation of seated work combined with periods of walking or standing). Additionally, the posture of the manikin should be adjusted by flexing the movable joints to obtain required body posture and resulting realistic clothing draping. The ambient conditions can be constant during the exposure or changed by adjusting the climatic setpoints or moving the thermal manikin from one room to another.

The quantitative statistical evaluation of the predicted data allows comparing the system's reliability in various exposures which is crucial to assess the overall performance of the system. The accuracy of both thermo-physiological and thermal sensation predictions can be assessed by calculating the root-mean-square deviation (rmsd) and the bias [44]. An rmsd value lower than the average standard deviation of the experimental data indicates that the human simulator test's results fit well to the values from the human subject study. When no standard deviation values from the experiment is provided, the accuracy is considered to be acceptable when the rmsd is lower than the typical standard deviation of the parameter (i.e., $0.2^{\circ} \mathrm{C}$ and $1.0^{\circ} \mathrm{C}$ for core and mean skin temperature [44], and 1 unit for thermal sensation votes [54]). The bias should be equal or close to zero for unbiased predictions, and not higher than the standard deviation of the experimental data. Negative values of bias represent an average over-prediction, and positive values an average under-prediction of the assessed parameter. In the case of the rmsd, it can be used for assessing the accuracy in single cases, as well as for the average reliability based on a group of exposures (mean rmsd). The mean bias, calculated for a group of exposures, is a valuable indicator of systematic over- or underprediction of a parameter. 


\subsection{Validation examples}

For this study, five exposures from two human subject studies have been selected from the literature (Schellen et al. [55], Kakitsuba and White [56]) to evaluate the performance of the human simulator for predicting thermal sensation in the built environment following the validation procedure described in Section 2.2. Both thermo-physiological measurements (i.e., mean skin and rectal core temperature) and thermal sensation votes were reported for all selected exposures. A detailed description of the exposures' conditions is presented in Table 1. The metabolic activity corresponded to seated office-type work (1.1-1.2 met, as reported in the two studies), and the duration of all exposures was at least 8 hours, representing an average working day. Besides steady-state environmental conditions in exposure 1 and 2 (Table 1), two types of transient conditions were included, such as air temperature ramps and stepchanges. In the exposure with air temperature ramps, the temperature was gradually changed at a rate corresponding to $2 \mathrm{~K} /$ hour (exposure 3, Table 1 ). In exposures 4 and 5 (Table 1 ), the air temperature was changed in a stepwise manner, with changes corresponding to $0.5 \mathrm{~K}$ every hour (step-change increase and decrease in exposure 4 and 5, respectively. From the study by Schellen et al. [55] (exposures 2 and 3, Table 1) only the data from young subjects were included, in order to not introduce a possible source of bias related to age.

Table 1 Description of the conditions and measurements for each exposure, with the range of environmental and personal conditions

\begin{tabular}{llcccccc}
\hline No. & & $\mathbf{1}$ & $\mathbf{2}$ & $\mathbf{3}$ & $\mathbf{4}$ & $\mathbf{5}$ \\
\hline Type & & & Steady-state & Steady-state & Tair ramp & $\begin{array}{c}\text { Tair step- } \\
\text { change }\end{array}$ & $\begin{array}{c}\text { Tair step- } \\
\text { change }\end{array}$ \\
\hline Duration & & (hours) & 9 & 8 & 9 & 9 & 8 \\
\hline Environmental & Tair & $\left({ }^{\circ} \mathrm{C}\right)$ & 28 & 21.5 & $17 / 25$ & $26 / 30$ & $30 / 26$ \\
parameters & Trad & $\left({ }^{\circ} \mathrm{C}\right)$ & Tair $^{1}$ & Tair & Tair & Tair $^{1}$ & Tair $^{1}$ \\
& RH & $(\%)$ & 60 & 43 & 43 & 60 & 60 \\
& vair & $(\mathrm{m} / \mathrm{s})$ & $0.2^{1}$ & 0.19 & 0.19 & $0.2^{1}$ & $0.2^{1}$ \\
\hline Subjects & Number & $(\mathrm{M} / \mathrm{F})$ & $10 / 0$ & $8 / 0^{2}$ & $8 / 0$ & $10 / 0$ & $10 / 0$ \\
\hline Personal & Activity & $(\mathrm{met})$ & $1.2^{3}$ & 1.2 & 1.2 & $1.2^{3}$ & $1.1^{3}$ \\
parameters & Icl & $(\mathrm{clo})$ & 0.1 & 0.9 & 0.9 & 0.1 & 0.1
\end{tabular}


ACCEPTED MANUSCRIPT

\begin{tabular}{|c|c|c|c|c|c|c|c|}
\hline & Ret & $\left(m^{2} \mathrm{~Pa} / \mathrm{W}\right)$ & 5 & 22 & 22 & 5 & 5 \\
\hline \multirow{2}{*}{$\begin{array}{l}\text { Measurement } \\
\text { type }\end{array}$} & Tcore & (type) & rectal & rectal & rectal & rectal & rectal \\
\hline & mTsk & $\begin{array}{l}\text { (no. of } \\
\text { points) }\end{array}$ & 7 & 14 & 14 & 7 & 7 \\
\hline \multirow{3}{*}{$\begin{array}{l}\text { Thermal sensa- } \\
\text { tion votes }\end{array}$} & Scale & (type) & - & continuous & continuous & - & - \\
\hline & & $\begin{array}{l}\text { (no. of } \\
\text { points) }\end{array}$ & 7 & 7 & 7 & 7 & 7 \\
\hline & Votes & $\begin{array}{l}\text { (votes per } \\
\text { person) }\end{array}$ & 20 & 17 & 17 & 20 & 20 \\
\hline Source of data & & & $\begin{array}{c}\text { Kakitsuba } \\
\text { and White } \\
{[56]}\end{array}$ & $\begin{array}{c}\text { Schellen et } \\
\text { al. [55] }\end{array}$ & $\begin{array}{c}\text { Schellen et } \\
\text { al. [55] }\end{array}$ & $\begin{array}{c}\text { Kakitsuba } \\
\text { and White } \\
{[56]}\end{array}$ & $\begin{array}{c}\text { Kakitsuba } \\
\text { and White } \\
{[56]}\end{array}$ \\
\hline
\end{tabular}

Tair - air temperature, Trad - mean radiant temperature, RH - relative humidity, vair - air velocity, Icl, clothing thermal insulation, Ret - clothing evaporative resistance, Tcore - core temperature, mTsk - mean skin temperature, TS - thermal sensation, M/F - male/female subjects

${ }^{1}$ Assumed values of Trad and vair (not reported in the reference)

${ }^{2}$ Tcore and mTsk values were reported for all eight subjects, whereas thermal sensation votes were reported only for one subject

${ }^{3}$ Average metabolic heat production calculated as the average from four 1-hour measurement periods The Rct and Ret values have been selected based on the description of the experiments and typical values from the literature $[57,58]$ and they include both clothing ensemble and chair

In a first step, the exposures were simulated with the thermoregulation model alone (Taitherm $v$ 11.2, Thermoanalytics, US) to determine the initial surface temperature set-points for the manikin. For these simulations, all input parameters were taken as described in the experimental protocols of the exposures including any reported pre-exposure conditions (Table 1). In a second step, the human simulator tests with the 'Newton' manikin controlled by the thermoregulation model were performed, with the manikin pre-heated to the initial local temperatures as predicted by the thermoregulation model alone (in step 1). The environmental conditions were reproduced in a climatic chamber, similar clothing and chair as used in the experimental study were applied, and two repetitions for most of the exposures were made. It has to be noted that the coupled tests for exposures 4 and 5 (Table 1 ) were performed in a chamber allowing only $1^{\circ} \mathrm{C}$ steps, this is why the air temperature was adjusted by $1^{\circ} \mathrm{C}$ every two hours instead of $0.5^{\circ} \mathrm{C}$ every hour as in the original subject study. In a third step, the virtual simulations, i.e. in the thermoregulation model only, were repeated with the 
same input environmental parameters as measured in the climatic chamber during the test with the thermal manikin to increase the correspondence between the two types of tests and enable a comparison between the results from both methods. Thermal sensation predictions from DTS and TS models were calculated both from virtual simulations' and human simulator tests' results.

The statistical parameters (rmsd and bias) were calculated for mean skin and core temperature, as well as for the thermal sensation predictions from both DTS and TS models. Since the standard deviation of the mean value was reported only for core temperature measurements for exposures 1,4 , and 5 (standard deviation equal to $0.2,0.3$ and $0.3^{\circ} \mathrm{C}$, respectively), the accuracy of each parameter was assessed to be acceptable when the rmsd was smaller than the typical standard deviations from human subject studies. These typical values for mean skin temperature, core temperature, and thermal sensation are reported in the literature to be equal to $1.0^{\circ} \mathrm{C}, 0.2^{\circ} \mathrm{C}$, and 1 thermal sensation unit, respectively $[12,27,44,54]$. 


\section{Validation results}

The results from the validation examples are summarized in Figure 2. For each exposure, the mean skin and rectal temperatures, as well as thermal sensation as provided from the human subject studies are plotted against predictions from virtual simulations (thermoregulation model only, with environmental input parameters as in the human simulator test) and human simulator tests. The air temperature as set in the experiment is presented together with the air temperature recorded during the human simulator tests in the climatic chamber. The statistical analysis, i.e. calculated rmsd and bias for core and mean skin temperature, as well as for thermal sensation predictions from DTS and TS models, are summarized in Table 2. 


\section{Exposure 1}

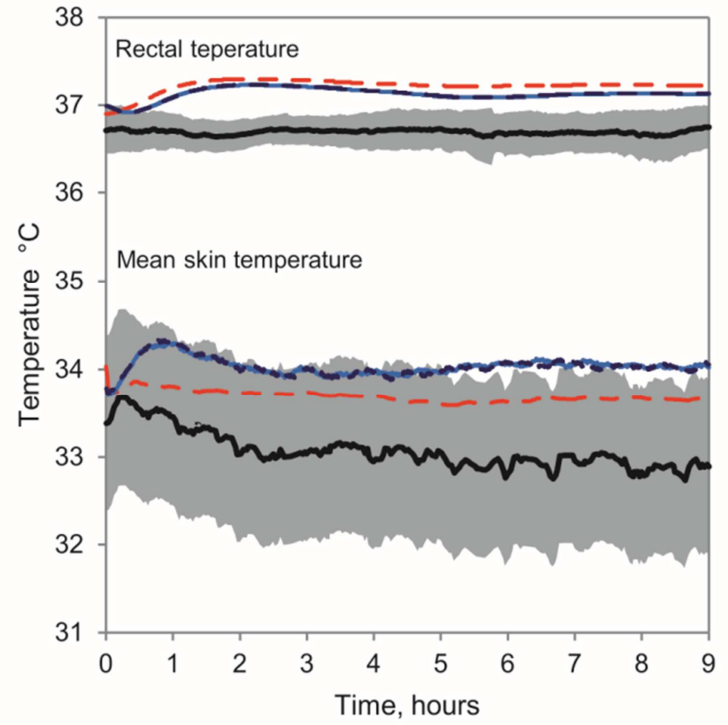

\section{Exposure 2}

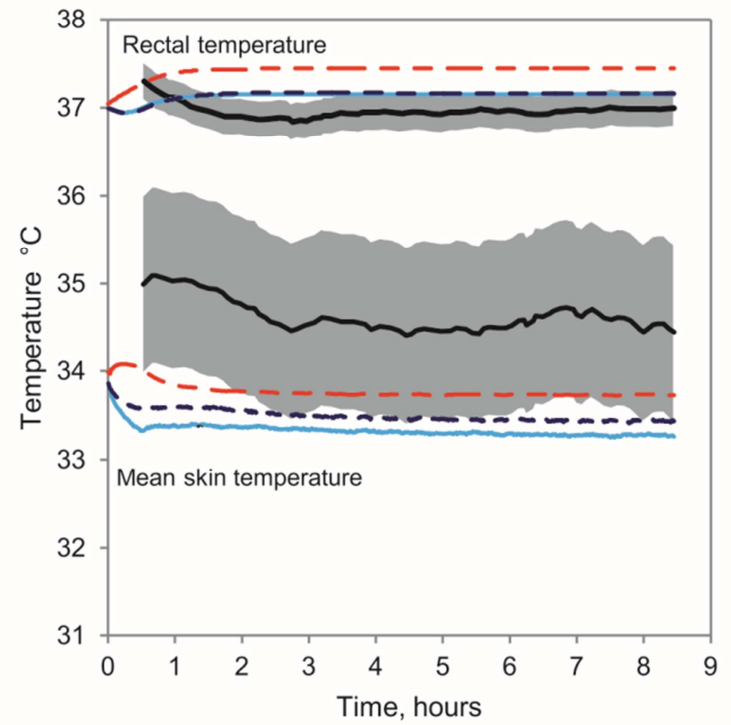

\section{Exposure 3}

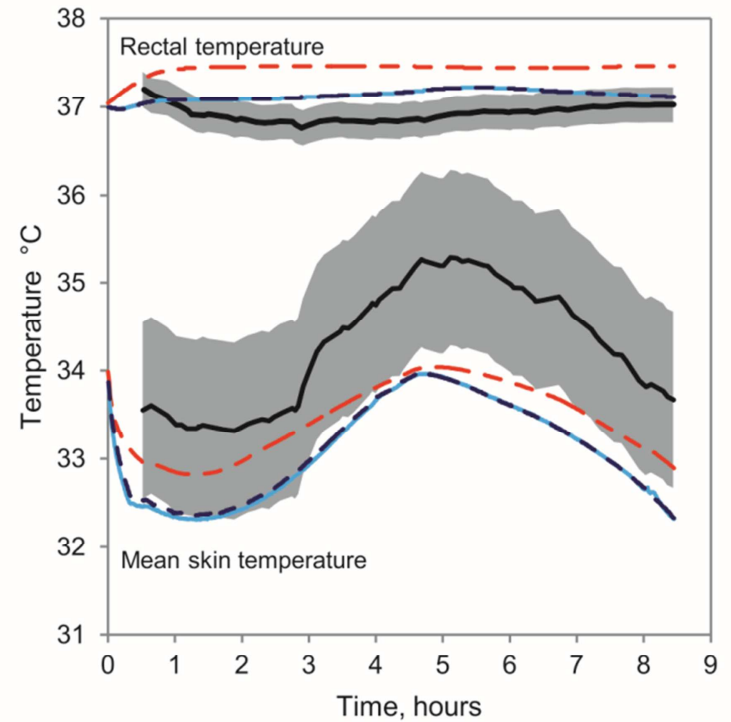

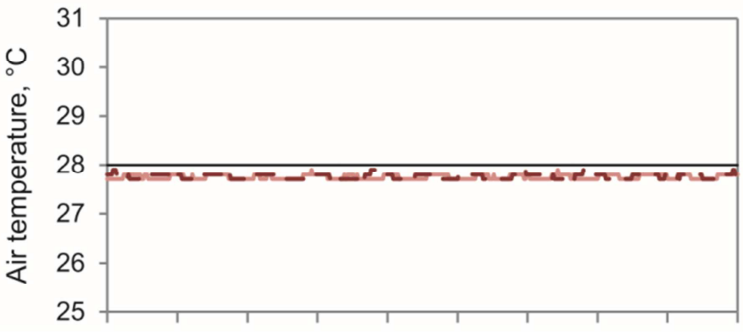
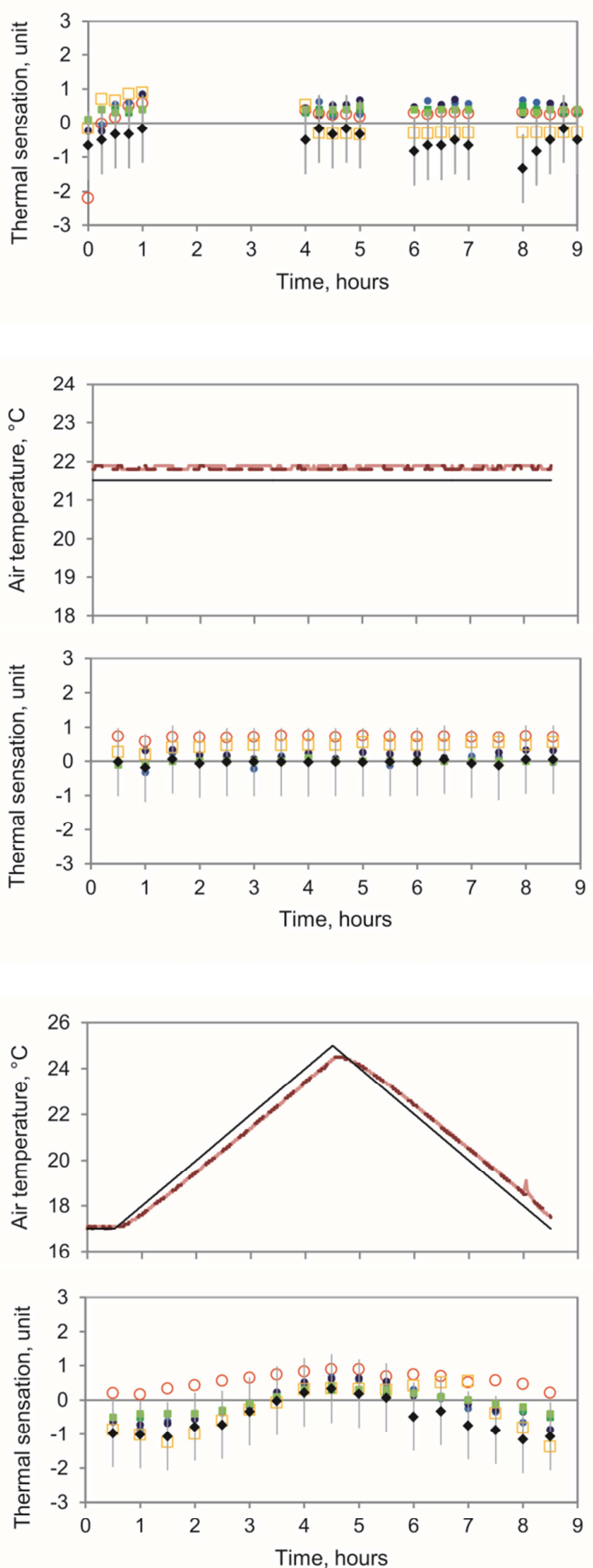
Exposure 4
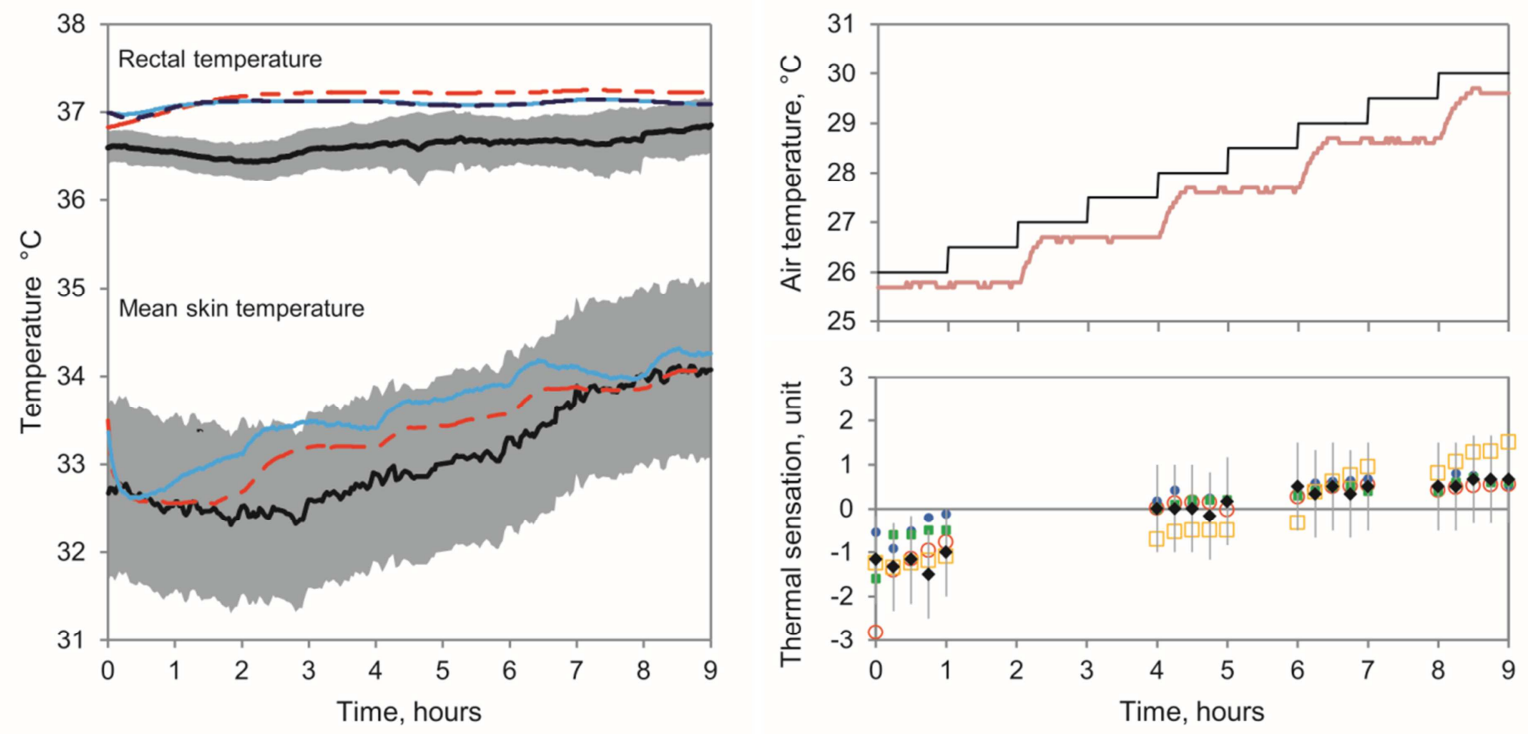

Exposure 5
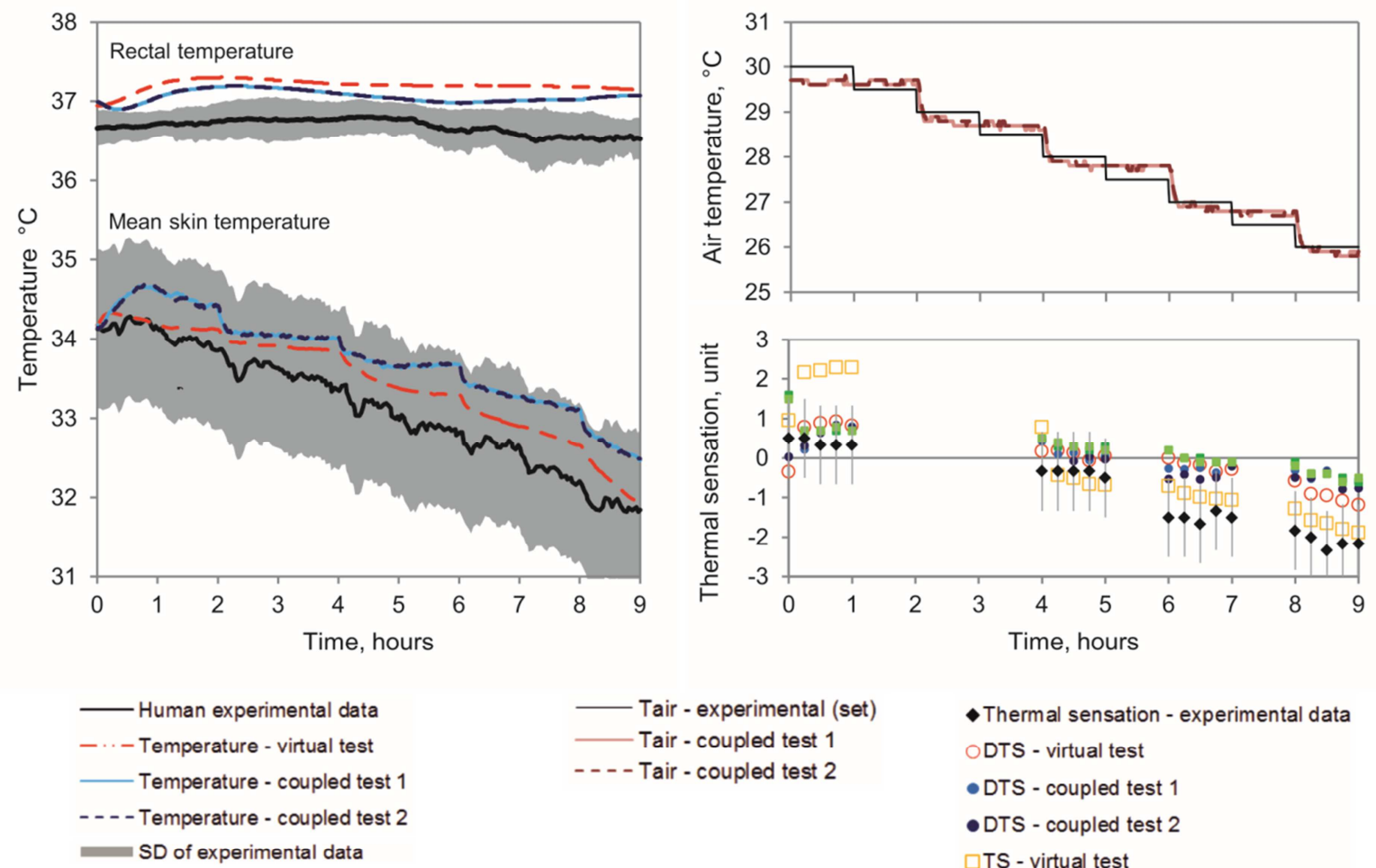

- Thermal sensation - experimental data

ODTS - virtual test

-DTS - coupled test 1

-DTS - coupled test 2

$\square T S$ - virtual test

-TS - coupled test 1

-TS - coupled test 2

Figure 2 Summary of validation examples results: the experimental data, virtual simulation results (in the thermoregulation model only) and human simulator test results are plotted together for mean skin, rectal, and air temperature, and thermal sensation; DTS - Dynamic thermal sensation by Fiala [9], TS - Thermal sensation by Zhang et al. [10,14]; SD - standard deviation of experimental data (or typical value for the parameter, if not provided) 


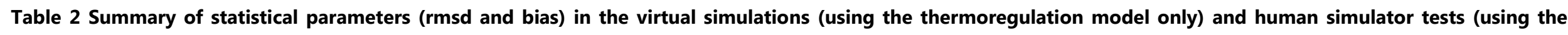

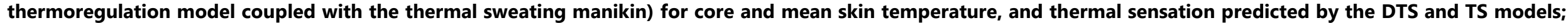
each row represents one repetition

\begin{tabular}{|c|c|c|c|c|c|c|c|c|c|c|c|c|c|c|c|c|c|}
\hline \multirow[t]{4}{*}{ No. } & \multirow{4}{*}{$\begin{array}{l}\text { Type of } \\
\text { exposure }\end{array}$} & \multirow{2}{*}{\multicolumn{4}{|c|}{$\begin{array}{c}\text { Physiological parameters }\left({ }^{\circ} \mathrm{C}\right) \\
\text { Tcore }\end{array}$}} & & \multicolumn{11}{|c|}{ Thermal sensation (thermal sensation unit) } \\
\hline & & & & & & & & & & & & TS & & & & & \\
\hline & & \multicolumn{2}{|c|}{ Virtual test } & \multicolumn{2}{|c|}{ Human simulator } & \multicolumn{2}{|c|}{ Virtual test } & \multicolumn{2}{|c|}{ Human simulator } & \multicolumn{2}{|c|}{ Virtual test } & \multicolumn{2}{|c|}{ Human simulator } & \multicolumn{2}{|c|}{ Virtual test } & \multicolumn{2}{|c|}{ Human simulator } \\
\hline & & rmsd & bias & rmsd & bias & rmsd & bias & rmsd & bias & rmsd & bias & rmsd & bias & rmsd & bias & rmsd & bias \\
\hline \multirow{2}{*}{1} & \multirow{2}{*}{ Steady-state } & 0.53 & -0.52 & 0.44 & -0.43 & 0.64 & -0.61 & 0.97 & -0.95 & 0.9 & -0.7 & 1.0 & -0.9 & 0.7 & -0.5 & 0.9 & -0.9 \\
\hline & & 0.53 & -0.52 & 0.44 & -0.43 & 0.64 & -0.62 & 0.97 & -0.95 & 0.9 & -0.7 & 1.0 & -0.9 & 0.7 & -0.5 & 0.9 & -0.9 \\
\hline \multirow{2}{*}{2} & \multirow{2}{*}{ Steady-state } & 0.48 & -0.47 & 0.21 & -0.18 & 0.88 & 0.87 & 1.32 & 1.31 & 0.7 & -0.7 & 0.1 & -0.1 & 0.5 & -0.5 & 0.1 & 0.0 \\
\hline & & 0.48 & -0.47 & 0.22 & -0.19 & 0.89 & 0.88 & 1.15 & 1.14 & 0.7 & -0.7 & 0.2 & -0.2 & 0.5 & -0.5 & 0.1 & 0.0 \\
\hline \multirow{2}{*}{3} & \multirow{2}{*}{ Tair ramp } & 0.54 & -0.53 & 0.24 & -0.22 & 0.90 & 0.85 & 1.21 & 1.19 & 1.1 & -1.1 & 0.4 & -0.4 & 0.5 & -0.2 & 0.5 & -0.4 \\
\hline & & 0.54 & -0.53 & 0.24 & -0.22 & 0.91 & 0.86 & 1.19 & 1.17 & 1.1 & -1.1 & 0.4 & -0.4 & 0.5 & -0.2 & 0.5 & -0.5 \\
\hline 4 & Tair step-change & 0.56 & -0.55 & 0.48 & -0.47 & 0.36 & -0.26 & 0.62 & -0.53 & 0.4 & 0.0 & 0.5 & -0.3 & 0.5 & 0.0 & 0.4 & -0.1 \\
\hline \multirow{2}{*}{5} & \multirow{2}{*}{ Tair step-change } & 0.53 & -0.52 & 0.39 & -0.38 & 0.34 & -0.31 & 0.63 & -0.60 & 1.0 & -0.8 & 1.1 & -0.9 & 1.0 & -0.7 & 1.2 & -1.1 \\
\hline & & 0.53 & -0.52 & 0.39 & -0.38 & 0.35 & -0.31 & 0.63 & -0.60 & 1.0 & -0.8 & 1.0 & -0.8 & 1.0 & -0.7 & 1.2 & -1.1 \\
\hline
\end{tabular}

rmsd - root-mean-square deviation, Tcore - core temperature, mTsk - mean skin temperature, DTS - dynamic thermal sensation by Fiala, TS - thermal sensation by Zhang 


\section{Discussion}

\subsection{Validation examples outcome}

The qualitative analysis of the results (Figure 2) shows that the predicted thermal sensations from both pure virtual and human simulator tests follow similar trends as the experimental data. It has to be noted that the TS model is based on an extended 9-point scale (i.e., different than the one used in the experimental studies and for DTS predictions), however, there is no standardized approach for comparing results from different scales $[59,60]$. Therefore, we assumed that the "core" 7-points of the two scales are equivalent (i.e., the two additional extreme points in the 9-point scale do not change the predictions in the "core" 7-points).

Since the standard deviations for thermal sensation votes were not reported in the references, the predictions are assumed to be accurate when the rmsd is lower than 1 unit, which can be considered the typical inter- and intra-subject variability in human subjects [54]. Therefore, it can be concluded from the results in Table 2 that the thermal sensation predictions from the DTS and TS models were accurate in most cases, with rmsd values lower than 1 unit (with the exception of DTS from virtual simulation in exposure 3, and DTS and TS from human simulator test in exposure 5, Table 2). As pre-exposure conditions are often not exhaustively described in papers and assumptions have to be made, a mismatch to the experimental data for the first data-points can be expected (e.g., DTS predictions - virtual test, first data-point in exposures 1,4 , and 5, Figure 2). The mean rmsd was equal to 0.9 and 0.6 units for DTS, and 0.6 and 0.6 units for TS in virtual and human simulator tests, respectively. The presented results show that both the virtual and human simulator tests led to satisfactory accuracy of thermal sensation predictions from both models. However, due to the limited availability of experimental data and, as a result, small number of validation cases, it is not possi- 
ble to clearly determine whether the use of the human simulator significantly improves the accuracy of thermal sensation prediction.

Although the predicted thermo-physiological parameters were in a certain offset to the experimental data, the general trends of parameters are preserved (Figure 2). The predicted mean skin temperature for the semi-nude exposures $(1,4$, and 5 , Table 1$)$ was higher than the experimental data, but fell within the typical standard deviation from human subject studies (rmsd lower than $1^{\circ} \mathrm{C}$ for both virtual and human simulator tests, Table 2). In the case of the clothed exposures ( 2 and 3, Table 1$)$, the predictions are below the mean skin temperature measured in the experiment (rmsd approximated 0.9 and $1.2^{\circ} \mathrm{C}$ for virtual simulation and human simulator test, respectively). Since the typical standard deviation for mean skin temperature is considered to be $1^{\circ} \mathrm{C}$ [44], the results can be considered to be satisfactory, with the values from the human simulator tests showing a lower accuracy (mean rmsd for mean skin temperature equal to 0.66 and $0.97^{\circ} \mathrm{C}$ for virtual and human simulator tests, respectively).

The predicted core temperature was higher than the experimental data for all five exposures, with the predictions from human simulator tests being more accurate than the ones from the virtual simulations (mean rmsd for core temperature predictions in all five exposures was equal to 0.53 and $0.34^{\circ} \mathrm{C}$ for pure virtual and human simulator tests, respectively). The accuracy of core temperature predictions was slightly lower than the typical standard deviation (i.e., $0.2-0.3^{\circ} \mathrm{C}[44]$, which complies with the reported standard deviation for core temperature in exposure 1, 4, and 5, listed in Section 2.3).

In order to carry out tests and properly interpret results obtained with a human simulator it is crucial to understand the capabilities and limitations of such tools. Depending on the goal of the test (e.g. validation of the human simulator for predicting thermal sensation, comparison 
of indoor environment conditions created with different HVAC systems), various aspects will play a critical role in planning the measurements and analyzing the acquired results. The presented validation examples illustrate how thermal sensation prediction from tests performed with a human simulator can mimic the votes of a group of people, and are the foundation for a broader discussion of the challenges and opportunities of using human simulator in indoor environmental research in sections 4.2-4.5.

\subsection{Coupling method and parameters' accuracy}

Depending on the chosen coupling strategy, different issues causing predictions' inaccuracy should be considered. When local skin temperatures measured on the manikin are used to feed the thermo-physiological model (boundary conditions type 1), the heat fluxes to be set on the manikin cannot be directly equal to the metabolic heat production of the simulated human body due to the different heat capacity of the human tissues (bones, muscles, fat, skin etc.) and the manikin's shell. To compensate these differences, modified heat fluxes for the manikin need to be calculated. The approach developed by Curran et al. [30] and applied in the 'Newton'-Manikin PC ${ }^{2}$ system is based on calculating the heat flow in a control volume of skin tissue with the same thermal diffusivity as the thermal manikin's shell. In this way, the resulting manikin's surface temperatures match the ones predicted for a human body in identical environmental and clothing conditions. To implement such calculations, knowledge about the thermal capacity of the individual manikin segments is required, that is, about the amount of different materials in various body parts. However, the exact amount of material used might be difficult to determine and may vary between exemplars of the same manikin due to the mostly manual manufacturing process. An inaccurate estimation of the thermal properties of the manikin's segments would lead to over- or under-estimation of the heat flux set-points, which, in turn, would affect the resulting surface temperatures of the manikin. 
The use of manikin's measured heat flux as input for the thermoregulation model (boundary conditions type 2) brings another type of difficulty to consider as the manikins developed up to date are not equipped with surface heat flux sensors. Therefore, the manikin's heat flux is calculated as the heating power delivered to the manikin over its surface area. This method of calculation proves to be valid for steady-state tests and mild to moderate transients, however, it may not be appropriate for highly transient conditions. When the skin temperature change is higher/lower than that possible to obtain with the manikin's heating/cooling capabilities, the heating power ceases to be a good estimate for the heat flux. In such cases, the heating power might be set to its maximal value or to zero for a number of time-steps (for heating and cooling, respectively). This introduces false input values for the thermoregulation model by providing a heating power value different than required and omitting the heat flux associated with the heat storage capacity within the manikin shell. These false heat flux input values result in altered predictions of skin temperature and sweat rates by the thermoregulation model, which are then in turn set on the manikin surface, intensifying the prediction's uncertainty. In human simulator tests for the built environment, this could translate into prediction errors when simulating highly transient conditions, e.g. entering a cooled or heated building during a hot or cold day, respectively. Nevertheless, the thermo-physiological changes due to a change in metabolic rate are typically slower and do not pose a problem in human simulator tests (e.g. starting to walk after sitting).

A worse reliability of thermo-physiological predictions may be due to the manikin's local heat flux or surface temperature measurements. In steady-state measurements with constant surface temperature, the segmental heat flux variability results from both the manikin's own inaccuracy and the fluctuations of the ambient conditions. In the case of the 'Newton' manikin, the joint effect of these inaccuracies was found to be up to $\pm 3 \%$ deviation from the average 
local heat flux [61]. Moreover, the correctness of the surface temperature measurement of the manikin's calibrated sensors was found to differ not more than $0.2^{\circ} \mathrm{C}$ from the values measured by reference sensors [61]. To investigate the possible effect of the abovementioned inaccuracies in heat flux or surface temperature measurements on thermophysiological predictions, we performed two sets of simulation with the thermoregulation model of Fiala (FPCm5.3, Ergonsim, Germany - implementation allowing various boundary condition types) using either heat flux or skin temperature input values. As an example, we simulated exposure 4 with air temperature up-steps in its original version (Table 1). Then, the most unfavorable cases were simulated, i.e. with either local heat fluxes changed by $\pm 3 \%$, or local skin temperatures altered by $\pm 0.2^{\circ} \mathrm{C}$ on each body part.

Figure 3a) presents the predictions obtained based on the original heat fluxes predicted by the model, as well as the modified ones (input heat flux altered by $\pm 3 \%$ of local heat flux for each body part). In this example, modifying the heat flux input values resulted in mean skin temperature $0.6^{\circ} \mathrm{C}$ lower or $0.9^{\circ} \mathrm{C}$ higher than the original predictions after 9 hours of the simulated exposure $\left( \pm 0.4^{\circ} \mathrm{C}\right.$ after the first hour). The overall impact of the differences in heat flux input values would result in \pm 1.3 thermal sensation unit difference in DTS predictions at the end of the exposure. This is higher than the typical inter- and intra-subject variability [54] and indicates that the influence of heat flux measurement inaccuracy can substantially change thermal sensation predictions.

In the case of coupling the manikin with the thermoregulation model based on boundary conditions type 1 , the effect of changing input local skin temperatures by $\pm 0.2^{\circ} \mathrm{C}$ can be assessed indirectly by the core temperature predictions. Since the adopted approach fixes the local skin temperatures to a given temperature and the environmental conditions are given as well, changes in body heat storage will occur, influencing the internal body temperature. 
Figure $3 b$ ) shows that in exposure 4 the rectal temperature would change by $\pm 0.1^{\circ} \mathrm{C}$ if the mean skin temperature was changed by $\pm 0.2^{\circ} \mathrm{C}$, and DTS predictions could change up to \pm 0.6 units. This suggests that skin temperature measurements inaccuracies within such range have a smaller influence on thermal sensation predictions than heat flux inaccuracies (Figure 3a). However, since the mean skin temperature in this case is assigned to chosen values (i.e., $\pm 0.2^{\circ} \mathrm{C}$ of the originally predicted local skin temperature), the calculated DTS predictions result from both the resultant core temperature and the "fixed" skin temperature values. Nevertheless, these two examples show how inaccuracies in the parameters measured/set on the manikin could influence the thermo-physiological predictions and, in turn, thermal sensation predictions.
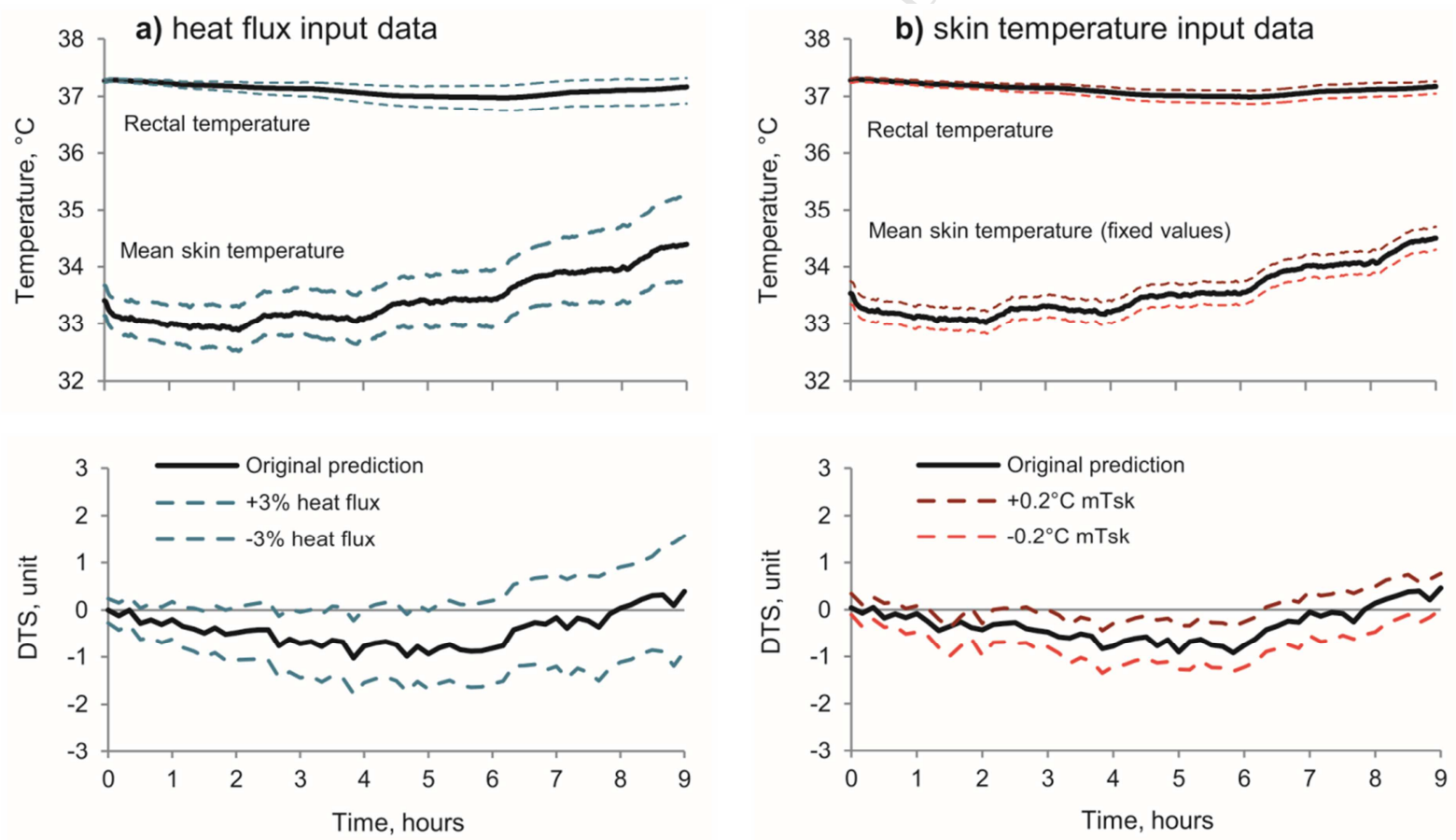

Figure 3 Influence of inaccuracy in input data on thermo-physiological and thermal sensation predictions (shown on the example of exposure 4, Table 1); a) local heat fluxes changed by $\pm 3 \%$, b) local skin temperatures changed by $0.2^{\circ} \mathrm{C}$ 


\subsection{Use of real garments}

Human simulator tests, in comparison with purely virtual simulations, benefit from thermophysiological predictions founded on the real environmental conditions and clothing. Thermoregulation models typically consider only few static clothing parameters, such as thermal and evaporative resistance, and clothing area factor. Values for predefined ensembles, as well as for single garments, can be found in standards or in the literature $([58,62])$, however, these are provided as one whole-body value. In order to make thermo-physiological simulation more realistic, assumptions about the local clothing thermal resistances have to be made. This is a complicated task, since ensembles with similar whole-body thermal clothing insulation can have very different local insulation values. Veselá et al. [63] collected four studies with reported global and local clothing thermal insulation, showing the differences in local skin temperature predictions between similar ensembles. The mean skin temperature was shown to differ by up to 1.11 and $0.73^{\circ} \mathrm{C}$ (in the case of operative temperature equal to 22 and $26^{\circ} \mathrm{C}$, respectively) [63], which could possibly lead to a change in thermal sensation predictions of approximately 0.5 unit (estimation based on the sensitivity of DTS predictions for comparable clothing and metabolic rate in similar conditions reported in [12]). However, the influence of local clothing properties on the local skin temperatures is much stronger, resulting in a shift of predicted local thermal sensation (depending on the body part; e.g., 3 units for feet or 1 unit for upper arm [63]). Such differences in local thermal sensation predictions can burden the evaluation of indoor conditions, e.g. a 'hot' sensation of the feet (due to higher local insulation applied) instead of 'neutral' may lead to conclusion that the temperature of a heated floor needs to be lowered. To prevent possible misinterpretation, human simulator tests with real garments are necessary and, in the case of virtual simulation, using 
measured local clothing properties is advised (from thermal manikin measurements or for ensembles described in literature, e.g., [64]).

Another advantage of human simulator tests is including the real effect of posture and chair on the heat transfer between the human body and its surroundings. The ISO 9920 standard provides clothing thermal insulation values for a standing posture [58], with some general information about the estimated change in whole-body insulation due to the seated posture and chair (based on the findings of McCullough et al. [57]). Since the posture influences the thickness of air trapped between the body and the clothing differently for various body parts [65], the additional insulation provided by these air gaps varies across the body. Therefore, the estimation of the clothing and chair insulation for a seated posture based on data for standing posture is troublesome. On the contrary, the human simulator tests are at once integrating the heat transfer resulting from the real clothing and chair, as well as the body posture. In Figure 4a), a comparison of a scenario simulated in the thermoregulation model with different clothing input parameters is shown (exposure with air temperature equal to $25^{\circ} \mathrm{C}$, relative humidity equal to $50 \%$, still air, and metabolic level equal to 1.2 met). Using air gap thickness and contact area data from the study by Mert et al. [65] and calculating the resulting clothing resistance according to [66], we applied three sets of clothing parameters describing exactly the same ensemble (long-sleeve shirt and sweat pants, loose fit), namely:

- with one global clothing thermal insulation value for standing posture $(0.78 \mathrm{clo})$, resulting from averaging the local clothing resistance values,

- with local clothing properties for a standing posture,

- with local clothing properties for a sitting posture (including the chair insulation). 
For this steady-state scenario, the differences in mean skin temperature predictions were not higher than $0.1^{\circ} \mathrm{C}$ (Figure 4a), resulting in small changes in DTS predictions (>0.1 unit). The small global differences between a standing and seated posture are related to the compensation of the decreased insulation for body parts where the air layer was reduced (e.g. front thigh or front lower arm) by the additional chair insulation for other body parts (e.g. back, or back thigh). However, the difference in local skin temperature between standing and sitting posture for the body parts in contact with the chair equaled $0.8-1.2^{\circ} \mathrm{C}$, which for this example would change the local thermal sensation predictions by approximately 0.5 unit. The influence of clothing input parameters could be even more important when using more complex clothing ensembles or highly insulating chair.
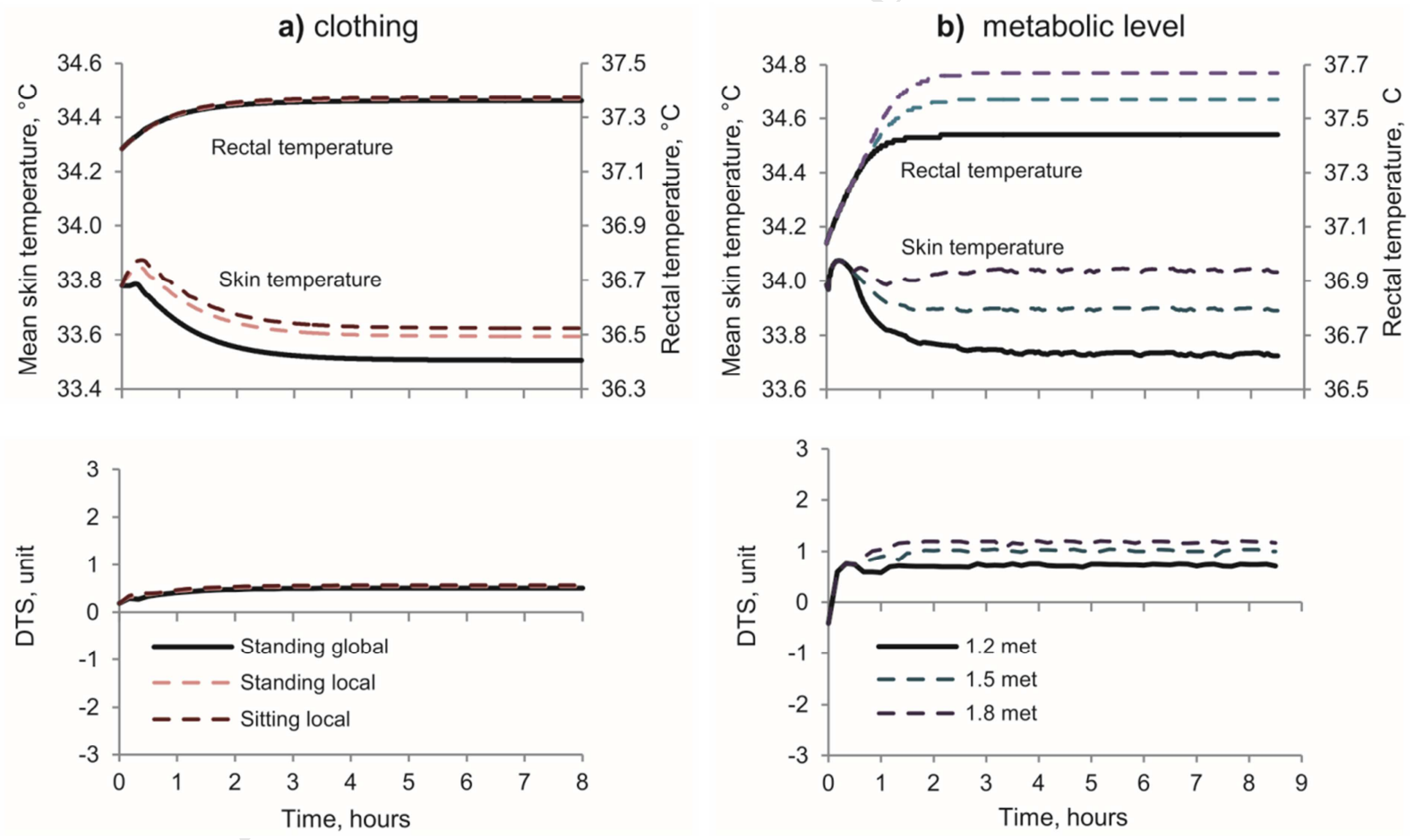

Figure 4 Influence of clothing and metabolic level input data on thermo-physiological and thermal sensation predictions; a) exposure in $25^{\circ} \mathrm{C}$ and still air conditions with activity corresponding to 1.2 met, with the clothing defined based on global or local parameters for a standing posture, and on local parameters for a seated posture [65]; b) exposure 2 (Table 1) simulated with three metabolic levels, namely 1.2, 1.5, and 1.8 met 
When performing a human simulator's validation, it is essential to carefully choose the clothing, as the original experiment ought to be reproduced in all details. The best solution is to use the same garments as used in the experimental study, adjusting it to match the clothing fit (if needed). However, this may be difficult when the experiments chosen for a validation study have been performed in another laboratory, or even impossible in the case of subjects wearing their private clothing. Therefore, the clothing ensemble often has to be reproduced based on a short list of garments or pictures taken during tests with human subjects. The thermal insulation of garments used in the experiment, if reported, is frequently an assumed standard value (according to ISO 9920 [58]) or might have been measured in a different body posture (e.g. standing instead of seated).

When performing human simulator tests to evaluate environmental conditions in designed indoor environments, the used garments should simply reflect a realistic combination of clothing. Since every person might have different clothing preferences, the aim is to choose a typical ensemble which can be representative for what one could wear in a given situation. For example, summer or winter ensembles should be chosen to match the investigated conditions. Moreover, the dress-code can be taken into account if applicable (e.g. business suits for conference rooms, uniforms dedicated for certain occupations, etc.). This approach is sufficient for comparative measurements with different HVAC systems, where the differences in thermal perception of an average person are analyzed.

\subsection{Activity level}

In virtual simulations as well as in human simulator tests, the metabolic level related to the performed activity needs to be given as an input value since it affects both core and skin temperature. Besides the whole-body metabolic level typically used as input for thermoregu- 
lation models, the local distribution of heat production also plays a vital role in the correct simulation of human thermo-physiology. The latter is reflected by pre-defined coefficients that allocate the whole-body heat production onto individual body parts, which vary between thermoregulation models. However, these coefficients usually do not take into account the variety of possible activities engaging different muscles, or even different postures. By comparing the same scenario simulated with three different sets of local heat production coefficients, Veselá et al. [63] found differences in predicted mean skin temperature up to $0.3^{\circ} \mathrm{C}$, with local skin differences up to $1.3^{\circ} \mathrm{C}$. Although the difference in mean skin temperature is not substantial, the local thermal sensation predictions could shift approximately 1 thermal sensation unit, impairing the evaluation of complex, heterogeneous environments (see Section 4.3). In order to ensure that both global and local metabolic heat production is applied correctly in the thermo-physiological simulation, it is necessary to validate the thermoregulation model not only for mean skin temperature value, but also for local skin temperatures for typical occupations in the built environment whenever possible.

During the validation of a human simulator for predicting thermal sensation, the proper attribution of metabolic level is needed to reproduce best the human subject experiments. Experiments where the metabolic rate has been measured instead of assumed from available standard values are preferred (e.g. ISO 7730 [48]). However, such measurements are seldom done in the case of office work or the measurement is not done continuously (e.g. exposures 1,4 , and 5 where the metabolic heat production was measured for four 1 -hour periods). In the case of exposures 1 and 3 (Table 1 ) where the subjects performed office tasks, the metabolic level was assumed by the authors to be equal 1.2 met (corresponding to 'sedentary activity (office, dwelling, school, laboratory)' according to ISO 7730 [48]). However, higher metabolic levels attributed to seated office work can be found in the literature. In the 
'Compendium of Physical Activities' provided by Ainsworth et al. [67], 1.5 met is described as the metabolic level corresponding to 'sitting tasks, light effort (e.g. office work, (...) computer work, (...) reading, desk work)' (average measured value from six studies reported in the literature). To show the possible implications of choosing a different metabolic level for the same activity on thermo-physiological and thermal sensation predictions, additional simulations were done with the thermoregulation model (Taitherm v11.2, Thermoanalytics, US). Instead of the originally assumed 1.2 met, a metabolic level of 1.5 met was set for exposure 2 (value according to [67]), keeping the other input parameters as in the original simulation. Additionally, a higher metabolic rate equal to 1.8 met was chosen to illustrate the changes in mean skin temperature and DTS predictions, which are presented in Figure 4b) for the three metabolic rates selected (1.2 met as reference 'original' simulation, 1.5 , and 1.8 met, respectively). The mean skin temperature increased approximately $0.15^{\circ} \mathrm{C}$ with each 0.3 met increase of the metabolic level. Such changes would results in a shift of DTS predictions equal to 0.3 and 0.5 units for 1.5 and 1.8 met in comparison with the 'original' 1.2 met simulation, respectively. Such a shift in whole-body thermal sensation prediction does not substantially change the evaluation of the indoor conditions (corresponding to 'slightly warm' according to the ASHRAE 7-point scale [49]). However, in the case of a human simulator validation even such small changes might be meaningful, especially if more than one source of discrepancies between the experiment and the coupled test could occur simultaneously (e.g. scarce information about the clothing used and no measurement of metabolic heat production in the reference human subject study).

\subsection{Sweating simulation}

The simulation of sweating in human simulators poses some challenges on the thermal manikin, as it needs to be properly realized in all phases of sweating, namely, the onset of sweat- 
ing, fully-developed sweating, and drying of the wetted skin. When a tight-fitting fabric skin is used to spread the sweating water delivered to the manikin's surface, the heat exchange between the manikin and its surrounding is altered as this fabric is an additional layer not present in the case of a human being. Although some equations to correct the manikin's surface temperature for the skin insulation have been developed, they are only applicable for a fully-wetted fabric skin [68-71]. Since the thermal insulation of the fabric changes with its wetness (from its maximal insulation in dry state to its minimal value when fully-wetted [72]), an adjustable correction factor to account for the fabric skin is needed. However, the wetness of the skin cannot be measured by the existing thermal manikins. In the case if no correction is applied, the highest discrepancy between the manikin's surface temperature and the temperature of the outer surface of the skin will occur for scenarios with low sweat rates, when the insulation added by the fabric skin is highest. Contrarily, applying a fixed-value correction based on the dry fabric thermal resistance would lead to highest inaccuracies in scenarios with high sweat rates.

Another issue related to the use of a fabric skin is the possibility of moisture migration. If the evaporation of sweat occurred on another segment than the sweating itself, the segmental temperatures would be affected due to the shifted cooling effect. Such discrepancies in local temperatures have increasing consequences in heterogeneous environments, changing the local thermal sensations, e.g., in a naturally-ventilated building with a fan used for local cooling of the face and upper chest. If some greater sweat migration to lower body parts occurred, the cooling effect from the higher air speed would be lower, leading to higher local thermal sensation predictions. 


\subsection{Opportunities for environmental engineering}

The specifics of the human simulator make it a promising tool to acquire data for predicting thermal sensation in complex environments including realistic effects of body posture and its orientation, as well as insulation and air flow interruption of a chair and other furniture in the body's surrounding. At the enclosure level, the influence of the spatial and temporal distribution of environmental conditions (air and radiant temperatures, temperatures of contact surfaces, air velocity, and solar load) on the human well-being can be directly measured with the spatial body resolution of the human simulator. For example, the integral effect of radiant and convective (natural and forced) heat exchange between such elements as walls, heated floors, cooling beams, radiators, and solar load through glazing and irradiated surfaces could be addressed. On the other hand, the temporal development of these phenomena combined with the dynamic reaction of the human body such as increased sweating, moisture accumulation in the clothing, increased body heat storage and change of skin temperature distribution can be simulated in real-time.

The human simulator can be regarded as an intermediate step between pure virtual simulations and human subject trials and, therefore, could prove helpful when comparing various prototypes and combinations of HVAC and other building systems with regards to the occupants' perception of the resultant thermal conditions. On one hand, such a solution represents a high realism of the exposure in the actual environment (unlike purely virtual simulations), and, on the other hand, it is extremely time efficient as compared to human trials, while providing either the same or higher level of output details (e.g. local skin temperatures, sweat rate, thermal sensation). Human simulator tests can also be helpful for the evaluation of existing building, e.g., during building's refurbishment or to evaluate layout changes within the building since the new layout may not always agree with the designed distribution of en- 
vironmental conditions. Therefore, the human simulator approach may support the evaluation of multiple potential layouts, e.g., while rearranging open space offices.

Although using a human simulator for predicting thermal sensation eliminates the need for virtual simulation of the surroundings and clothing, some sources of predictions' inaccuracy are present, as described in Sections 4.2-4.5. It can be expected that the total inaccuracy can be, in the most unfavorable case, the joint effect of all the limitations of the human simulator, as well as from the used thermal sensation model itself.

\section{Conclusions}

A methodology for the use of a human simulator for predicting occupants' thermal perception in the built environment has been proposed in this study. The combination of three tools, namely, a thermal manikin, a thermoregulation model, and a thermal sensation model enables the assessment of how occupants may feel in complex heterogeneous environments. The possibility of evaluating local thermal sensation creates a powerful tool for engineers and designers of indoor spaces, allowing identifying the possible sources of discomfort at the design stage or during the evaluation of existing buildings. In this study, the performance of such a human simulator was shown on five examples of seated exposures in office-like conditions, demonstrating that thermal sensation can be predicted accurately based on such tests, with similar or better accuracy than in tests using a purely virtual approach (i.e., without a thermal manikin places in the assessed environment). It has to be noted however, that the advantages of the human simulator would possibly be more pronounced in spatially heterogeneous conditions. The major challenges and opportunities of performing human simulator tests have been discussed with respect to performing a validation of such a tool, as well as to future applications. 
Human simulators are promising tools for predicting thermal sensation in the built environment, being the bridge between simple initial simulations (e.g., for virtual buildings) and the evaluation of thermal conditions done by human subjects. Although they are not intended to entirely replace direct enquiry, human simulators can support the design process by decreasing the number of tests to be done with human subjects. They are, therefore, recommended especially for comparison tests of various solutions, such as prototypes of systems, or complex systems where optimal environmental parameters are sought.

\section{Acknowledgments}

The acknowledgments will be added after the review process to not disclose the authors' affiliation.

\section{Funding sources}

This research did not receive any specific grant from funding agencies in the public, commercial, or not-for-profit sectors.

\section{Conflict of interests}

None 


\section{References}

[1] N.E. Klepeis, W.C. Nelson, W.R. Ott, J.P. Robinson, A.M. Tsang, P. Switzer, J.V. Behar, S.C. Hern, W.H. Engelmann, The National Human Activity Pattern Survey (NHAPS): a resource for assessing exposure to environmental pollutants, Journal of Exposure Science and Environmental Epidemiology 11 (2001) 231-252.

[2] M. Veselý, W. Zeiler, Personalized conditioning and its impact on thermal comfort and energy performance-A review, Renewable and Sustainable Energy Reviews 34 (2014) 401-408.

[3] A. Burdick, Strategy Guideline. Accurate Heating and Cooling Load Calculations, IBACOS, Inc., Pittsburgh, PA (United States), 2011.

[4] R.F. Rupp, N.G. Vásquez, R. Lamberts, A review of human thermal comfort in the built environment, Energy and Buildings 105 (2015) 178-205.

[5] D. Fiala, Dynamic Simulation of Human Heat Transfer and Thermal Comfort, PhD thesis, De Monfort University Leicester, 1998.

[6] H. Zhang, Human thermal sensation and comfort in transient and non-uniform thermal environments, PhD thesis, University of California, Berkeley, 2003.

[7] Q. Jin, X. Li, L. Duanmu, H. Shu, Y. Sun, Q. Ding, Predictive model of local and overall thermal sensations for non-uniform environments, Building and Environment 51 (2012) 330-344.

[8] H. Nilsson, Comfort climate evaluation with thermal manikin methods and computer simulation models, PhD thesis, Royal Insitute of Technology, Sweden, 2004.

[9] D. Fiala, K. Lomas, M. Stohrer, First principles modeling of thermal sensation responses in steady-state and transient conditions, ASHRAE Transactions 109 (2003) 179-186.

[10] H. Zhang, E. Arens, C. Huizenga, T. Han, Thermal sensation and comfort models for nonuniform and transient environments, part III: Whole-body sensation and comfort, Building and Environment 45 (2010) 399-410, https://doi.org/10.1016/j.buildenv.2009.06.020.

[11] F.R.d.A. Alfano, B.I. Palella, G. Riccio, The role of measurement accuracy on the thermal environment assessment by means of PMV index, Building and Environment 46 (2011) 13611369.

[12] B. Koelblen, A. Psikuta, A. Bogdan, S. Annaheim, R.M. Rossi, Thermal sensation models: Validation and sensitivity towards thermo-physiological parameters, Building and Environment 130 (2018) 200-211, https://doi.org/10.1016/j.buildenv.2017.12.020.

[13] S. Gauthier. The role of environmental and personal variables in influencing thermal comfort indices used in building simulation. Conference proceedings: 13th Conference of International Building Performance Simulation Association (BS2013). 2013:2320-2325. 
[14] H. Zhang, E. Arens, C. Huizenga, T. Han, Thermal sensation and comfort models for nonuniform and transient environments: Part I: Local sensation of individual body parts, Build Environ 45 (2010) 380-388, https://doi.org/10.1016/j.buildenv.2009.06.018.

[15] A. Psikuta, J. Allegrini, B. Koelblen, A. Bogdan, S. Annaheim, N. Martínez, D. Derome, J. Carmeliet, R. Rossi, Thermal manikins controlled by human thermoregulation models for energy efficiency and thermal comfort research - A review, Renewable \& Sustainable Energy Reviews 78 (2017) 1315-1330.

[16] H. Sokolová, A. Psikuta, Using a human thermoregulation model as a tool for design and refurbishment of industrial spaces for human occupancy, Manuscript submitted for publication.

[17] T. Han, L. Huang, A sensitivity study of occupant thermal comfort in a cabin using virtual thermal comfort engineering, SAE Technical Paper, 2005.

[18] N. Gao, H. Zhang, J. Niu, Investigating indoor air quality and thermal comfort using a numerical thermal manikin, Indoor and built environment 16 (2007) 7-17.

[19] C. van Treeck, J. Frisch, M. Pfaffinger, E. Rank, S. Paulke, I. Schweinfurth, R. Schwab, R. Hellwig, A. Holm, Integrated thermal comfort analysis using a parametric manikin model for interactive real-time simulation, Journal of Building Performance Simulation 2 (2009) 233-250.

[20] L. Schellen, M.G.L.C. Loomans, B.R.M. Kingma, M.H. de Wit, A.J.H. Frijns, W.D.v.M. Lichtenbelt, The use of a thermophysiological model in the built environment to predict thermal sensation Coupling with the indoor environment and thermal sensation, Build Environ 59 (2013) 10-22, https://doi.org/10.1016/j.buildenv.2012.07.010.

[21] ASTM, ASTM F1291-16 Standard Test Method for Measuring the Thermal Insulation of Clothing Using a Heated Manikin, American Society for Testing and Materials, West Conshohocken, PA, 2016.

[22] S. Tanabe, E.A. Arens, F. Bauman, H. Zhang, T. Madsen, Evaluating thermal environments by using a thermal manikin with controlled skin surface temperature, Ashrae Transactions 100 (1994) 39-48.

[23] E. Foda, K. Siren, A thermal manikin with human thermoregulatory control: Implementation and validation, International Journal of Biometeorology 56 (2012) 959-971, https://doi.org/10.1007/s00484-011-0506-6.

[24] E. Foda, K. Sirén, Design strategy for maximizing the energy-efficiency of a localized floorheating system using a thermal manikin with human thermoregulatory control, Energy and Buildings 51 (2012) 111-121. 
[25] A. Psikuta, M. Richards, D. Fiala, Single-sector thermophysiological human simulator, Physiological Measurement 29 (2008) 181-192, https://doi.org/10.1088/0967-3334/29/2/002.

[26] A. Psikuta, Development of an 'artificial human' for clothing research, PhD thesis, De Monfort University Leicester, 2009.

[27] A. Psikuta, L.-C. Wang, R.M. Rossi, Prediction of the Physiological Response of Humans Wearing Protective Clothing Using a Thermophysiological Human Simulator, J. Occup. Environ. Hyg. 10 (2013) 222-232.

[28] J.P. Rugh, J. Lustbader, Application of a sweating manikin controlled by a human physiological model and lessons learned, in. J. FAN (ed.) Thermal Manikins and Modelling, 2006, 303-312.

[29] A. Psikuta, M.G.M. Richards, R. Rossi. Multi-sector thermo-physiological human simulator for clothing research. Proceedings of the 4th European Conference on Protective Clothing. 2009:24.

[30] A. Curran, S. Peck, M. Hepokoski, R. Burke. Physiological model control of a sweating thermal manikin. Proceedings of the 10th International thermal manikin and modelling meeting (10I3M). 2014:7-9.

[31] A. Psikuta, M. Weibel, R. Burke, M. Hepokoski, T. Schwenn, S. Annaheim, R.M. Rossi. A systematic approach to the development and validation of adaptive manikins. Proceedings of the XVI International conference of environmental ergonomics. 2015:30.

[32] R. Burke, A. Curran, M. Hepokoski. Integrating an active physiological and comfort model to the Newton sweating thermal manikin. Environmental Ergonomics XIII. Proceedings of the 13th International Conference on Environmental Ergonomics, Boston, Mass. 2009:2-7.

[33] K. Blood, R. Burke. Further Validation of the model-controlled Newton thermal manikin against historical human studies. Proceedings of the 8th International Meeting for Thermal Manikin and Modeling (813M), Victoria, Canada. 2010.

[34] R. Burke, K. Blood, A.S. Deaton, R. Barker. Application of model-controlled manikin to predict human physiological response in firefighter turnout gear. Proceedings of the 8th International Meeting for Thermal Manikin and Modeling (8I3M), Victoria, Canada. 2010.

[35] B. Redortier, T. Voelcker. Implementation of thermo-physiological control on a multi-zone manikin. Proceedings of the 8th International Meeting for Thermal Manikin and Modeling (8I3M), Victoria, Canada. 2010.

[36] B. Redortier, T. Voelcker. A 38-zone thermal manikin with physiological control: validation for simulating thermal response of the body for sports exercise in cold and hot environment. Proceedings of the 14th International Conference on Environmental Ergonomics (ICEE), Nafplio, Greece. 2011:99. 
[37] J. Yang, W. Weng, M. Fu, Coupling of a Thermal Sweating Manikin and a Thermal Model for Simulating Human Thermal Response, Procedia Engineering 84 (2014) 893-897.

[38] N. Martínez, Multi-sector thermophysiological head simulator for headgear research, PhD thesis, Universitat Politècnica de València, 2015.

[39] N. Martínez, A. Psikuta, J.M. Corberán, R.M. Rossi, S. Annaheim, Multi-sector thermophysiological head simulator for headgear research, International Journal of Biometeorology 61 (2017) 273-285, https://doi.org/10.1007/s00484-016-1209-9.

[40] A. Psikuta, K. Kuklane, A. Bogdan, G. Havenith, S. Annaheim, R.M. Rossi, Opportunities and constraints of presently used thermal manikins for thermo-physiological simulation of the human body, International journal of biometeorology 60 (2016) 435-446.

[41] B. Koelblen, A. Psikuta, A. Bogdan, S. Annaheim, R.M. Rossi, Comparison of fabric skins for the simulation of sweating on thermal manikins, International journal of biometeorology 61 (2017) 1519-1529, https://doi.org/10.1007/s00484-017-1331-3.

[42] D. Fiala, K.J. Lomas, M. Stohrer, A computer model of human thermoregulation for a wide range of environmental conditions: the passive system, Journal of Applied Physiology 87 (1999) 1957-1972.

[43] D. Fiala, K.J. Lomas, M. Stohrer, Computer prediction of human thermoregulatory and temperature responses to a wide range of environmental conditions, International Journal of Biometeorology 45 (2001) 143-159, https://doi.org/10.1007/s004840100099.

[44] A. Psikuta, D. Fiala, G. Laschewski, G. Jendritzky, M. Richards, K. Blazejczyk, I. Mekjavic, H. Rintamaki, R. de Dear, G. Havenith, Validation of the Fiala multi-node thermophysiological model for UTCI application, Int. J. Biometeorol. 56 (2012) 443-460.

[45] N. Martínez, A. Psikuta, K. Kuklane, J.I.P. Quesada, R.M.C.O. de Anda, P.P. Soriano, R.S. Palmer, J.M. Corberán, R.M. Rossi, S. Annaheim, Validation of the thermophysiological model by Fiala for prediction of local skin temperatures, International journal of biometeorology 60 (2016) 1969-1982.

[46] A. Psikuta, M. Weibel, B. Koelblen, M. Hepokoski, R. Burke, S. Annaheim, R. Rossi, Validation of Human thermal module in TAItherm and PC2 software for use in clothing and environmental research, Manuscript in preparation.

[47] A. Psikuta, M. Hepokoski, R. Burke, T. Schwenn, R. Rossi. A methodology for the validation of thermo-physiology models and adaptive manikins. 10th International Meeting on Thermal Manikin and Modelling (10i3m). 2014. 
[48] ISO 7730, Ergonomics of the thermal environment - Analytical determination and interpretation of thermal comfort using calculation of the PMV and PPD indices and local thermal comfort criteria, International Standards Organisation, Geneva, 2005.

[49] ASHRAE 55-2017, Thermal environmental conditions for human occupancy, American Society of Heating, Refrigeration and Air Conditioning Engineers (ASHRAE Standard 55-2017), 2017.

[50] K. Velt, H. Daanen, Thermal sensation and thermal comfort in changing environments, J. Build. Eng. 10 (2017) 42-46.

[51] A. Yasuoka, H. Kubo, K. Tsuzuki, N. Isoda, Interindividual differences in thermal comfort and the responses to skin cooling in young women, J. Therm. Biol. 37 (2012) 65-71.

[52] Z. Zhang, Y. Zhang, E. Ding, Acceptable temperature steps for transitional spaces in the hothumid area of China, Building and Environment 121 (2018) 190-199.

[53] S. Van Craenendonck, L. Lauriks, C. Vuye, J. Kampen, A review of human thermal comfort experiments in controlled and semi-controlled environments, Renewable and Sustainable Energy Reviews 82 (2018) 3365-3378.

[54] M.A. Humphreys, J.F. Nicol, The validity of ISO-PMV for predicting comfort votes in every-day thermal environments, Energ. Buildings 34 (2002) 667-684.

[55] L. Schellen, W.D.v.M. Lichtenbelt, M.G.L.C. Loomans, J. Toftum, M.H. de Wit, Differences between young adults and elderly in thermal comfort, productivity, and thermal physiology in response to a moderate temperature drift and a steady-state condition, Indoor Air 20 (2010) 273-283, https://doi.org/10.1111/j.1600-0668.2010.00657.x.

[56] N. Kakitsuba, M.D. White, Effect of change in ambient temperature on core temperature during the daytime, International Journal of Biometeorology 58 (2014) 901-907, https://doi.org/10.1007/s00484-013-0673-8.

[57] E.A. McCullough, B.W. Olesen, S. Hong, Thermal insulation provided by chairs, ASHRAE Transactions 100 (1994) 795-804.

[58] ISO 9920, Ergonomics of the thermal environment - Estimation of thermal insulation and water vapour resistance of a clothing ensemble, International Standards Organisation, Geneva, 2007.

[59] B. Koelblen, A. Psikuta, A. Bogdan, S. Annaheim, R.M. Rossi, Thermal sensation models: a systematic comparison, Indoor Air 27 (2017) 680-689.

[60] M. Schweiker, X. Fuchs, S. Becker, M. Shukuya, M. Dovjak, M. Hawighorst, J. Kolarik, Challenging the assumptions for thermal sensation scales, Building Research \& Information 45 (2017) 572-589. 
[61] M. Weibel, Performance evaluation of a thermal manikin coupled with a model of human thermal physiology, PhD thesis, ETH Zürich, Department of Health Sciences and Technology, 2014.

[62] E. McCullough, A data base for determining the evaporative resistance of clothing, ASHRAE Transactions 95 (1989) 316-328.

[63] S. Veselá, B. Kingma, A. Frijns, Local thermal sensation modeling-a review on the necessity and availability of local clothing properties and local metabolic heat production, Indoor air 27 (2017) 261-272.

[64] S. Veselá, A. Psikuta, A.J.H. Frijns, Local clothing thermal properties of typical office ensembles under realistic static and dynamic conditions, Manuscript submitted for publication.

[65] E. Mert, A. Psikuta, M.-A. Bueno, R.M. Rossi, The effect of body postures on the distribution of air gap thickness and contact area, International journal of biometeorology 61 (2017) 363-375.

[66] E. Mert, A. Psikuta, M.-A. Bueno, R.M. Rossi, Effect of heterogenous and homogenous air gaps on dry heat loss through the garment, International journal of biometeorology 59 (2015) 17011710.

[67] B. Ainsworth, W. Haskell, S. Herrmann, N. Meckes, D. Bassett Jr, C. Tudor-Locke, J. Greer, J. Vezina, M. Whitt-Glover, A. Leon. The Compendium of Physical Activities Tracking Guide [Online]. College of Nursing \& Health Innovation, Arizona State University: Healthy Lifestyles Research Center. Available: https://sites.google.com/site/compendiumofphysicalactivities/ [Accessed 23.10.2017].

[68] F.-M. Wang, K. Kuklane, C.-S. Gao, I. Holmér, G. Havenith, Development and validation of an empirical equation to predict wet fabric skin surface temperature of thermal manikins, Journal of Fiber Bioengineering and Informatics 3 (2010) 9-15, https://doi.org/10.3993/jfbi06201002.

[69] F. Wang, K. Kuklane, C. Gao, I. Holmér, Development and validity of a universal empirical equation to predict skin surface temperature on thermal manikins, J Therm Biol 35 (2010) 197203, https://doi.org/10.1016/j.jtherbio.2010.03.004.

[70] F. Wang, K. Kuklane, C. Gao, I. Holmer, Effect of temperature difference between manikin and wet fabric skin surfaces on clothing evaporative resistance: how much error is there?, Int J Biometeorol 56 (2012) 177-182, https://doi.org/10.1007/s00484-011-0411-z.

[71] S. Ueno, S.-i. Sawada, Correction of the evaporative resistance of clothing by the temperature of skin fabric on a sweating and walking thermal manikin, Text Res J 82 (2012) 1143-1156, https://doi.org/10.1177/0040517511427966. 
[72] F. Wang, W. Shi, Y. Lu, G. Song, R.M. Rossi, Effects of moisture content and clothing fit on clothing apparent 'wet' thermal insulation: A thermal manikin study, Textile Research Journal 86 (2016) 57-63. 
- Concept of validation and use of human simulators for predicting thermal sensation.

- Evaluation of complex conditions with advanced thermal sensation models.

- Capabilities and limitations of human simulators for indoor environmental research.

- Validation examples of the only commercially available human simulator system. 